\title{
Experiences of Turkish University Students on Academic Mobility: Before and after Academic Mobility Factors"
}

\author{
Hale Erden \\ Faculty of Education, Cyprus Social Sciences University, Nicosia, Mersin 10, Turkey
}

Copyright $\bigcirc 2016$ by authors, all rights reserved. Authors agree that this article remains permanently open access under the terms of the Creative Commons Attribution License 4.0 International License

\begin{abstract}
Student academic mobility is described as the movement of students from one country to another for studying undergraduate and/or graduate degrees. Students' academic mobility involves two factors: before academic mobility factors and after academic mobility factors. The current study aims at identifying the perceptions of Turkish university students regarding before academic mobility and after academic mobility factors. The study adopted an interpretive methodology under qualitative research paradigm. Focus-group-interviews(FGIs) and in-depth-interviews(I-DIs) were applied for data collection process. Focus-group-members(FGMs) were 50-TUSs studying at various departments and various universities in NC. FGIs were applied to identify factors contributing to before academic mobility and after academic mobility factors. I-DIs were taken place with 60-different-Turkish-university-students(dTUSs) studying at various departments of universities in NC to identify the common before academic mobility and after academic mobility factors. Interpretive approach was applied for data collection process and data were analysed through content analysis. Results reveal that Turkish university students experience pull and push factors as before academic mobility factors. Additionally, faced factors and expected factors are identified as part of the after academic mobility factors. In conclusion, pull factors involve educational-quality, personal-contribution and adaptation-quality. Similarly, push factors include departmental-issues, familiarities, family and country factors. Also, faced factors contain factors regarding finance, difficulties and dangers whereas expected factors involve factors regarding campus-quality and valuing-the-self.
\end{abstract}

Keywords Academic Identity, Learning and Personal Growth, Pull and Push Factors, Sense of Academic Belonging, Student Engagement

\section{Introduction}

This research paper reports the findings and discusses the results of a research project investigating the experiences of Turkish university students (TUSs) who are carrying out their undergraduate and graduate studies at five universities in North Cyprus. Students' academic mobility is defined as "the ability to move freely or be easily moved" [43]. Beaven and Golubeva [6] reveal that mobility of university students makes it possible to develop intercultural experiences for higher education students. The driving force for accepting mobility is mostly based on the "social networks of friendship and kinship" [7]. International students having such kind of social networks of both friends and family, intentionally or unintentionally, decide to study overseas ([7]; [14]). Higher education's main objective is to provide service to higher education itself, which is an open access discipline [28]. The experiences of TUSs were discussed in terms of factors contributing to before academic mobility factors and after academic mobility factors. The article explored the influence of their intercultural adaptation and inquired into how these influences effect them during their stay in NC by identifying the factors contributing to their academic mobility reasons as before academic mobility and after academic mobility factors. The current study seeks to identify the perceptions of TUSs on factors contributing to their academic mobility to NC in terms of before academic mobility factors and after academic mobility factors. Importance of identifying the perceptions of Turkish students regarding before academic mobility and after academic mobility factors contributing to their academic mobility to study in North Cyprus are important because this kind of identification gives rise to strongly contribution to finding out how to deal with the before and after academic mobility factors of Turkish university students, how to handle with their problems and/or issues they face/experience and expect, and explore and deal with additional management issues in relation to the identified factors. 
Academic mobility brings engagement and sense of belonging for the university students. Both engagement and sense of belonging involve engagement and sense of belonging to host country, culture, local people, academic and local environment, language, accommodation, transport and/or communication. In this study, perceptions of Turkish university students regarding before academic mobility factors and after academic mobility factors contributing to their academic mobility to study in NC are identified.

Turkish university students reveal pull factors and push factors contributing to their academic mobility to study in $\mathrm{NC}$ as part of before academic mobility factors. They also reveal faced factors and expected factors as part of after academic mobility factors. In this sense, the study has sought to find out what the Turkish university students report about before and after academic mobility factors contributing to academic mobility to NC.

\subsection{Conceptualizing the context}

This study conceptualizes the framework within the borders of student engagement and sense of academic belonging to higher education.

\subsection{The engagement dimension of higher education}

Academic performances of the students are affected by various factors. Higher level of integration to the university, self-efficacy and students' responsibility in employment has valuable contribution on student success at higher education [42]. Student engagement is the "generic indicator of quality learning and teaching and successful outcomes" [58]. Student engagement has various types such as "online, self-managed, peer and student-staff engagement" [36]. Student engagement supported by teaching staff-student engagement; teaching staff-subject engagement and teaching staff-teaching process engagement has been required. Sheard, Carbone and Hurst [51] categorize three features of students' engagement as "behavioural, cognitive and affective". It is firmly believed that students' level of engaging to the higher education process has influence on students' success and learning [35],[58]. Without engaging to the processes held in university, students cannot be successful. Thus, Baron and Corbin [4] suggest adoption of "whole-of-university approach" for increasing students' success throughout their higher education years. An engagement scale has found to involve 6 components, which are "valuing, sense of belonging, cognitive engagement, peer relationships (emotional engagement-I), relationships with the faculty members (emotional engagement-II) and behavioural engagement" [26]. Similarly, Kahu [35] suggests four influential points of views on student engagement which are behavioural, psychological, socio-cultural and the holistic point of views. These points of views range from student behaviour to institutional perspective to psychological social perspective, from sociological political perspective to general view of engagement.

There is positive proportion between higher levels of engagement to the higher levels of academic identity.
Mobility, change agent and being successful seek to changes at a positive glance. Similarly, academic identity has positive relationship between managerial and structural changes in the higher education [57]. Students' personal growth is the only indicator of higher levels of posttraumatic growth [12]. Personal growth has been defined as a "process having to do with the totality of the individual; it is always judged in terms of values" [31]. Unless showing signs of personal growth, the students may suffer from posttraumatic problems. Higher degrees of posttraumatic problems decrease the level of engagement of students to higher education. Students' self-knowledge and identity, talents, potential and their life quality are strongly affected by the personal growth. Personal growth covers life skills such as being honest, being tolerant, showing empathy, being in harmony with the environment and the self. Showing higher levels of personally grown skills feed the posttraumatic growth effectively.

\subsection{The sense of academic belonging dimension of higher education}

The sense focussing that power relationship shapes subjectivity in academics is widespread and common [49]. Students' self-esteem has an important role in shaping the sense of belonging of the students [40]. Sense of academic belonging affects school placement and development outcomes of the students [48]. A study confirms that there is a relationship between:

a) Students' sense of belonging and their academic self-efficacy, intrinsic motivation, and task value;

b) Students' sense of class-level belonging and their perceptions of instructors' warmth and openness, encouragement of student participation, and organization;

c) Students' sense of university-level belonging and their sense of social acceptance" [20].

Higher level of academic belonging to university supports positive increases in self-perceptions and supports decreases in problem behaviours especially with the international students [46]. Similarly, students' sense of belonging has positive relationship with teachers' promoting modified academic and interpersonal contexts in the classroom [2]. Estimating current academic situation in terms of grades and academic ability, estimating psychological adaptation in terms of self-worth and giving internal and external existence to problem behaviours are significant factors at belonging to the university [47].

Sense of academic belonging has positive relationship on academic growth of the students. It is confirmed that students' sense of belonging contributes to their academic motivation, engagement, and participation especially the groups who are under higher risk of dropouts from school [23]. Students' academic growth has connected to their motivation level, engagement level and participation level to the higher education process. These factors show level of responsibility taking of the students. Higher level of taking responsibility 
brings higher level of academic growth of the students. Various motivational measures, such as expecting success, giving value to schoolwork, having general motivation towards school and reporting self-effort, have strong connection to students' feel of school belonging.

\section{Methodology}

The current study adopted interpretive methodology as an epistemological position under quantitative paradigm. Phenomenology as the research design within interpretivism was used. Interpretive approach was used for qualitative data collection. The first stage of the study was focus group interviews (FGIs) with 50 Turkish university students (TUSs) from various departments and various universities in North Cyprus (NC). FGIs were applied to identify factors contributing before academic mobility and after academic mobility factors. In the second stage, in-depth interviews (I-DIs) were carried out with another 60 Turkish university students (dTUSs) from various departments and various universities in NC. I-DIs were applied to identify the common before mobility and after mobility factors. Semi-structured-interviews and I-DIs were applied as part of data collection methods.

50 focus group members (FGMs) participated to the Focus Group Interviews (FGIs). 60 in-depth interviewers participated to in-depth interviews (I-DIs). FGMs, university students coming from different parts of Turkey, were studying at various grades, various departments and various universities in NC. In-depth interviews were conducted with 60 different Turkish university students to make sure that identified factors contributing to before academic mobility and after academic mobility factors were common. The factor was eliminated unless it was common.

Semi-structured interview form-1 for FGMs was applied to the Turkish university students from university-1 to Turkish university students from university-5 (TUSfU1-TUSfU5) to identify the perceptions of Turkish university students regarding before academic mobility and after academic mobility factors contributing to their academic mobility to NC. Unstructured interview form-1 for participants was used for different Turkish university students from university-1 to different Turkish university students from university-5, (dTUSfU1-dTUSfU5) to identify whether identified factors were common or not. Throughout the process, data analysis results of FGIs and I-DIs were compared and common points were regarded as common factors.

Interpretive approach was used for qualitative data collection. Semi-structured interviews and in-depth interviews were applied as part of data collection methods. Data collected through interpretive approach were analyzed using content analysis method. Throughout the process, each participant of the study was assigned an ID. Through content analysis, data were put into categories and then themes and sub-themes were identified using the data by TUSfU1-TUSfU5 and dTUSfU1-dTUSfU5. Categories, themes and sub-themes were identified manual.

\subsection{Synthesis of data analysis}

The synthesis of findings to find out the factors and then the common factors aimed at increasing the validity and reliability of the study. Research instruments, semi-structured interview forms and unstructured interview forms, as well as data were reviewed by the experts from the field of educational sciences. Their comments shaped the ambiguous and uncertain questions. Their reviews also facilitated complex and unclear items to be re-worded in order to supply content validity. Additionally, their reviews helped removing or re-shaping the ineffective and non-functioning questions for face-validation of the questions in the research instruments.

\section{Findings and Discussion}

The findings of the research revealed how complex the experiences of the Turkish university students is in terms of the factors pulling and pushing them to study in NC (as before academic mobility factors) as well as in terms of faced and expected factors (as after academic mobility factors) they experience as university students in NC. These factors influenced students' chose throughout the process. Key findings will be presented under two categories: (1) before academic mobility factors, (2) after academic mobility factors and under four related key themes: (1) pull factors; (2) push factors; (3) faced factors and (4) expected factors.

\section{Category 1: Before academic mobility factors}

Before academic mobility factors involve pull factors and push factors. Pull factors cover educational quality, personal contribution and adaptation process. Similarly, push factors include student life and family factors, academic studies and departmental issues, familiarities and country factors.

\section{Theme 1: Pull factors}

Educational quality: TUSs felt excited on the opportunities for the education quality they would get. They believed that they would learn a foreign language in $\mathrm{NC}$ if they study an English-medium program, would get a peaceful student learning environment, would have an academic advising support and would have an academic reputation when they graduate.

I would like to improve my English, so I chose a faculty offering English medium instruction. Some of my instructors are abroad. Mostly, the instruction takes place in English. Some of the instructors unfortunately use Turkish, my native language, in class. I also studied foundation at the Preparatory School of my university (TUS8) 
As far as I graduate from the faculty, I will find a good job. I am sure I will have endless job opportunities because my university has an academic reputation not only in Turkey, but also in the world (TUS12).

... I have fruitful learning environment in the class and after class hours. I have some friends from foreign countries, we chat in English. This is beneficial in improving my listening and speaking skills (TUS32).

The instructors mostly provide good learning environment, which is beneficial in improving myself (TUS45).

European Universities supported by European Commission agree to accept procedures on quality assurance, take transparency measures on recognition and students' taking active part in the system [16]. Quality assurance in higher education requires overcoming problems regarding quality on culture, quality in compliance and quality in consistency [15]. Promoting educational quality in an institution is closely related to promoting quality assurance and overcoming quality assurance related problems. Higher education institutions need to develop mechanisms supporting quality assurance. Otherwise, it would not be possible to mention the educational quality of the institutions. Such kind of mechanism may include learning a foreign language at higher level, promoting a creative and fruitful student learning environment, having powerful academic advising support and developing academic reputation among the universities through level of research carried out within the university, level of qualified academic staff, level of students employability after graduation and level of institutions where graduates' employed.

Personal contribution: TUSs felt that they would have an opportunity to grow personally, would have sense of academic belonging, would have effective peer relationships and have academic career options.

... peer relationships... actually I have some confusions with this issue. Peer relationships are mostly confusing. Whenever I suffer from any issue, I feel that I grow. Whenever I have conflict with my friends, my soul grows. I gain experience in human relationships. It means that I grow personally (TUS1).

I am about to graduate... I am graduating from the faculty this February. I have a sense of academic belonging to my university. When I first came to the university, I felt very sad. Now, I am also sad. I don't want to leave my university now. I have sense of academic belonging to my university because this is the university I am graduating, which will never change. My peer relationships are perfect. I have grown personally while studying in this university (TUS46).

International students face some complexities. These complexities are mainly due to their maturation, development and their adaptation to the educational and local environment, culture and society. Maturation and development contribute to change and development of students through time. Change and development's nature and process are very valuable as nature and process of their change and development contribute to their maturation and human development over time. Similarly, students' adaptation, identity change and fundamental achievement are influenced by factors called personal factors, pedagogical factors, psychological factors, organizational factors and social culture factors [25]. Another study confirms that higher education students' intercultural adaptation has two dimensions which is the intercultural learning at another country, capacity to reveal intensive transforms in intercultural students themselves, and which is the transform of higher education students in terms of learning experience, having self-knowledge, being aware of the Other, being aware of values and being aware of the conception of the world [22].

Adaptation process: TUSs felt that they would have better holiday options on a paradise island, would easily grow an identity and would easily engage with domestic life in NC.

I have always believed the importance of learning and growing personally in a foreign country. This is one of the most important parts of the adaptation to the university, culture, country and people. I entered to the engineering department last year. There are lots of foreign students whose first language is not Turkish. I improve myself in English speaking skills especially, because I can practice my English with them. This is really beneficial for me. In this sense, the learning environment has been fruitful. There are other Turkish students studying at the faculty. I observe them. They choose their friends from foreign students. We have greater opportunities to improve our English. Personally, I have Turkish and Jamaican friends. We are usually at the same class and we generally go lunch together. We go to the library together. At our project weeks, and exam periods, we study together and we discuss issues together. We go to sea together, go to bazaar together to buy necessary vegetables and fruits; we share local life here, which I feel very safe myself with them (TUS23).

We study at an English medium instruction at university. .... Similarly, our lecturers have academic reputation. Our lecturers are friendly. We can contact them easily. I feel myself at home when I am at the faculty. I have started to the education faculty this year. They support me with their academic advice. I have grown an identity easily because my lecturers are very helpful in doing that. I live in a flat. I have neighbours from other flats, who are the local people of North Cyprus. Some afternoons, they send me some traditional meals they cook; or some Sundays, they invite me to their houses. This is very interesting. I found local people very friendly. Their hospitality is great for me. Cyprus is an island; I am on a paradise island; I can go to sea and take sunbath in the morning 
and then join my classes in the afternoon or vice versa. I like my studentship here in North Cyprus (TUS34).

A study suggests that higher education institutions are required to offer support to the students of various and diverse backgrounds at higher education in a way that they contribute to form a positive identity and develop a shared identity among the higher education students without paying attention to their class, ethnicity and/or religion [32]. Most students develop adaptation strategies for themselves. They adapt to the new rules as the game they play put ahead throughout the teaching and learning process as higher education students [38]. Students' characteristics such as their age, ethnicity, origins of country and personality aspects as well as their genuine supporting requirements should be explored to construct on students' educational improvement [5]. Being aware of the student identity, which develops through students' experience on higher education, gives rise to student engagement at the higher education and be ready to work when the students graduate [17]. Cultural learning, how to cope with stress and social identification are the dimensions of modern theoretical approaches, which are accommodated within a framework, named as "cultural synergy framework" basing upon the "affective, behavioural and cognitive aspects of shock and adaptation" and presenting wide range of comprehension [60].

Pull factors for studying in Malaysia have been identified as "comparatively low cost of living, low tuition fees, safe country for living, stable government modern amenities, proximity in culture and religion and freedom from discrimination"[1]. Identified pull factors give significant hints to the policy-makers to set up instructional facilities and establish impressive business strategies to attract more international students to Malaysia [1].

A study confirms pull and push factors for international higher education students related to "students' aspirations and expectations of international education". Factors influencing are "higher education institutions and their programmes" [3]. Another study identifies the satisfiers and unsatisfiers of international students' "individual performance, quality of educational service, socialization, and living conditions" [10]. Similarly, providing support services to higher education students facilitate sharing their experiences, their actual needs and helpful in increasing their satisfaction level of the international higher education students [50].

\section{Theme 2: Push factors}

Student life and family factors: TUSs were worried whether they will manage to adjust their financial situations, whether they will be alone or they will be able to make new friends and whether they will be able to join in a successful friendship environment, whether they will adjust their homesickness and whether they will love traditional Cypriot cuisine.

This is my second year in this country. At first I didn't have any financial problem. But, at the beginning of the second year, I faced some difficulties. I found a job at a hotel. I work as a part-timer. I earn some money; my mum sends me some money so that I can pay my fee. Life is not easy for me here because I have to earn money, join my classes, do my projects etc at the same time. I always feel homesick, but I know I will survive and graduate from the university (TUS18).

I am from far eastern parts of Turkey. I love spicy food. This is my first semester here. I cannot find meals fitting my palate. I cannot cook. I need to learn how to cook meals fitting my palate. I am homesick. I sometimes feel lonely; but I am a strong young boy. I will stay from beginning to the end; and will graduate from the university in North Cyprus. I think I am growing here (TUS38).

Most universities in North Cyprus are private and they require paying large amounts of fees. Paying fees brings quality management issues among the universities in North Cyprus since paying money is meant to pay to buy something. Among the difficulties, higher education students experience politicians' neglect of infrastructure, decline in enrolment, and harm on the quality of programme as well as the difficulties faced financially [44]. The research by Fengliang [18] suggests having a cost-sharing system in the higher education to form a powerful foundation in order to develop the higher education system throughout the country.

On the other hand, higher education students feel lonely themselves since most of them live away from their homes. Increased level of loneliness can lead to establish relationship orientation, have self-disclosure, have ability in building network and be passive. Students' level of relationship orientation has positive relationship to feeling of loneliness. Showing greater signs of self-disclosure means having felt loneliness at greater amounts. It is strongly suggested students communicate using online resources; higher education providers communicate new students before they arrive to the country; and higher education providers provide opportunities to students to use online and mobile resources as part of their social interaction [41]. Similarly, a study confirms that making harmonious friends is vital in retention. In fact, students' living arrangements have positive relationship with this process [55].

Academic studies and departmental issues: TUSs were also worried whether they would pass or fail their exams and would be successful in their essays, whether they would be able to join class discussions creatively, whether lecturers way of giving feedback affect their development, whether they would be able to establish relationships with lecturers, whether the lecturers would be able to understand their expectations. They were worried about the quality of lectures and teaching quality as well since they had a feeling that the university they chose would have the lowest scores upon entering the faculty might mean to have unqualified lecturers and lower level of teaching quality.

I have some worries. I am worried whether I will pass 
the class or not; I am worried whether I will be able to present the topic or the project in front of my friends; I am worried if someone asks me a question and I am unable to answer; I am worried if I failed from my exams or my essays. I want to be an active student; to volunteer to take part in discussions; be able to respond all questions properly. My worries can only overcome if my lecturers are perfect; I mean if they are good at giving lecturers; good at choosing the right project or essay parallel to the lecturer's aims and objectives. Lecturers and their teaching quality matter a lot (TUS5).

My worries regarding classes and lectures are the ones I see as dangers in front of me. I am worried about the essays and projects. If they are not appropriate for me, then I am unable to do them. Their availability means they should be in accordance with the lecture's goals and objectives. I feel embarrassed if I can't answer a question regarding my projectlessay. At first when I arrived at the university, I was feeling that I could do everything perfect without studying my lessons. I entered the university with lowest scores. However, I realized that my perception was not correct. I realised the importance of studying harder and harder; otherwise I am unable to trust myself and unable to understand my lessons. Studying harder, having qualified lecturers and qualified lectures are very important in being successful (TUS40).

Students' success on the assignments has close relationship with the extensive and detailed experience both in the home and host countries [53]. More experience brings more success to the students. Similarly, student development is closely related to the lecturers' method of giving feedback. Lecturers require considering the way they give feedback, nature of the comments and know the degree of feedback influencing the international students [54]. Higher education students' perspectives on higher education quality reveal that higher education adds value them rather than see them valuable from money perspective [34]. Student attrition is an important and a costly issue for higher education institutions. It negatively affects the reputation and expenses of the university. Higher education providers require addressing student attrition systematically, putting it into policy documents, sparing time and resources to deal with the nature of the attrition problems as well as develop strategies and policies [8]. Student attrition affects the student development, academic issues and departmental quality. Therefore, higher education providers should facilitate student development and student attrition systematically to remove any dangers might come due to them to academic studies and departmental issues.

Familiarities: TUSs were worried whether religious, cultural and language familiarities were for their advantage or not because they revealed that they mostly had similar religious, culture and language. Some cultural differences, degree of being conservative, being Muslim and/or mild
Muslim and some dialectical differences in the language they both use may occur. They were worried about these bits of pieces differences since small things might mean disadvantage for them.

I am Muslim, but I don't go to a mosque frequently. I go to mosque when it is a religious day. I am a mild Muslim. I have friends who are Atheist from other departments. They don't worship to any God. I also know some university students coming from Turkey, who are covered (for girls); who have long moustaches (for boys); who go to the mosque 5 times a day. I admire them, but I am not like them. I am not like the Atheist friends as well. I haven't felt any pressure from them on me, which is good; but they choose their friends among the students who are similar to them; similar to their clothing style, moustache style and living style. We worship Allah; the frequency we go to the mosque and the style of moustaches we have are different from each other. The religious we believe is the same (TUS16).

I am from western parts of Turkey. I have got some classmates from eastern parts of Turkey. Their cultural understanding and my cultural understanding may differ from each other. Turkey involves more than 75 million people. I believe cultural differences are quite normal for such a big country. However, we understand each other. Cultural familiarity with some differences in it is quite normal (TUS35).

One thing I need to clarify Turkish is the official language we use everywhere formally. However, there are some lingual differences; such as a student from Black Sea side of Turkey uses a different dialect, which is closer to Greek. When this student goes to a supermarket, he or she uses Turkish; but when he or she sees another student who is from the same region, they may prefer using their regional dialect. This is due to the cultural and dialectical varieties in Turkey. I think this shows the cultural and dialectical richness of Turkey. I haven't felt any pressure on me to use my regional dialect. I use it if I want to; it is up to me to decide whether to use my dialect or not (TUS20).

Brown and Holloway [13] agree that culture shock is the negative feeling towards the host country. However, Ben-Tsur [9] believes, "ideological and religious affiliation to a host country may motivate international student mobility". Similarly, being unfamiliar to religion, culture and language of the host country, international students will feel alienated and will face adaptation problems. However, familiarity to religion, culture and language of the host country offers easy adaptation and led academic student mobility occur at greater extend. Actually, harmful influence of culture shock can be decreased using strategies such as by giving information, being sensitive to culture, learning through doing and training social skills of the students [21]. However, some universities in North Cyprus hesitate to share the information with the students, most of the students are 
not sensitive to culture of the international students, most of lecturers only lecture throughout the semester; but they do not led the students to promote their research and social skills. Familiarities such as language, culture and/or religion for a higher education student mostly advantageous since the students do not feel culture shock. Instead, they may feel part of the culture, language and religion.

Country factors: TUSs are worried whether they will transport everywhere easily, whether it is easy to access everywhere, whether the host country has walking/biking places near main roads and whether the host country has local parks to spend time in the open air.

Before I arrived in North Cyprus, I was really worried about the transportation and communication availabilities. When I was a child, we had holiday in Karpazia; we couldn't even find a taxi or a telephone to call my grandparents who were in Turkey. We had to walk one kilometre to reach the sea. It was nice holiday, but it was very tiring for me. Now, I have my mobile with me; the university offers regular bus transfers for the students. Once I had to take a taxi. It was really expensive in Nicosia. In Famagusta, students can share taxi fee and take a taxi for their in-city-transfers. There is not a regular fee-schedule of taxis for students in North Cyprus (TUS22).

I like cycling. In Turkey, the high school I study was very closer to the apartment I was living. I was cycling to the school every day. It was fun and an advantage to do sports for me. Here the university I study is not far away from the flat I live. I want to cycle but it is really impossible to cycle in North Cyprus. There should be cycling roads near the main roads. However, there is none where I live. I desire to have such kind of opportunities for local people and for the students. Cycling is really inexpensive and gives us doing sport (TUS2).

I need to take fresh air after school, in my free time. Especially at exam weeks, I really need to be outside. However, there are not any parks for people around. I want to sip from my tea, to chat with my friends and to watch sea without thinking anything; but I don't want to pay much money for that (TUS11).

Country factors are unique factors to North Cyprus. Students mostly complain not having local parks to spend some valuable time with friends, not having walking/biking roads near main roads and/or alone and not having cheaper car hiring options. However, they believe that they mostly access university campus and libraries easily using the regular bus-services of the university.

\section{Category 2: After academic mobility factors}

After academic mobility factors include faced factors and expected factors. Faced factors cover factors on finance, difficulties and dangers. Additionally, expected factors give rise to factors on campus quality and valuing the self.

\section{Theme 3: Faced factors}

Finance: TUSs would face finance issues on cost of living and extras except tuition fees.

North Cyprus is an expensive country. It is not easy to survive for me in North Cyprus. I need to work to pay my tuition fee. I work in a casino as a part-timer. They pay me well. There are military canteens; most of the things in military canteens are exported from Turkey, but they don't pay anything to the custom. Military has such kind of advantage. Most of the things are cheaper in these canteens. I try my best to shop from these canteens. I have extra things to pay especially for my project materials and for my books. If I don't work, I am unable to survive (to pay my tuition fee, cost of living and pay for school project-materials, pay for my accommodation and communication etc.) in North Cyprus as a student (TUS50).

I don't work in North Cyprus; my family sends money for me to pay my tuition fee, to pay for my housing bills (accommodation; electricity, kitchen costs and so on), to make my living, to pay for my communication and transportation. There are inner-city transfers, but they are mostly not on time. I frequently need to call a taxi with my home mates. We share the taxi fee, which is less expensive then. Although the issue is like that for me, I can say that North Cyprus is an expensive country and university costs are very high (TUS43).

Harmonizing public higher education budget with private funding has been suggested to meet the increasing demand on higher education [45]. Similarly, Lee [37] reveals that there is an unclear distinction between public and private universities in terms of finance and control. Public universities have to deal with excess number of students especially. However, students from Turkey at higher education sector prefer North Cyprus universities mostly due to the lower base scores they have. Therefore, students require paying tuition fee to the university to study. They also require meeting their expenses. They agree that cost of living is high in North Cyprus.

Difficulties: TUSs would face difficulties such as lack of support in conducting research, lack of academicians' satisfaction, lack of sense of belonging of part-time lecturers, lack of effective office hours and lack of qualified teaching staff/PhD/Ed.D holder staff.

Last semester, I had Research Methods-II classes. The instructor put us in groups and gave us topics to research on. My topic was on the management issues the academicians face. I wanted to interview with the instructors in the faculty, but none of them was volunteer to interview with me. I also tried my best to contact the academicians at another university. Hearing that I was from X university, but not from their 
university, they didn't even show any desire to help me. I have a feeling that universities do not support each other in North Cyprus and even the lecturers do not want to spare their time for other lecturer's students. When I contacted them, I always asked for their office/free hours; some of them locked their doors at the time they promised to have the interview with me and some of them were in their offices but asked me to come later. It might be that they didn't want to talk about the management issues they face. My lecturer kindly asked them to provide their valuable time for the interview both in my faculty and at other university's faculties. I had the interviews with the instructors who agreed to help me at the end. I actually felt very sad because I was expecting everyone to help me voluntarily (TUS37).

I feel that most of the part-time lecturers do not have sense of belonging to the university. I observe them that they are not satisfied with the lessons they offer; mostly they are not prepared well to the classes. Some of them do not contribute to the academic and personal growth of the students. I don't know whether they are paid enough or not, but I think that they should spend their valuable time for the students. Not only part-time lecturers, but also some of the full-time lecturers do not obey the office hours. They either are not inside the office or they don't respond to the student voluntarily. As a student, you feel it. Most of the lecturers even do not have PhDs or EdDs. In Turkey, I very well know from my relatives that a lecturer who does not hold the proper degree (I mean PhD) on the subject field cannot teach at the university. They can only be assistants of a professor. They are not lecturers; they are assistants. In the universities of North Cyprus, most of the part-time lecturers are PhD students and masters' students. Most of them are recent graduates from masters' degree. I think a masters' or/and a PhD student should not teach at the university before they hold the PhD degree (TUS33).

Researchers and policy makers require answering the questions raised due to the development in higher education and problems posed in higher education. It is suggested that there should be further development in the specialized branch of knowledge of higher education for having a systematic approach in order to deal with the problems and issues aroused in the policy of higher education [59]. Thus, universities are expected to develop their students in research activities [24]. Difficulties faced by the higher education students in North Cyprus are related to not having enough support to carry out researches, academicians' not having satisfaction towards students, education and/or higher education in general, part-timers' not having sense of belonging to the university they teach totally, full-timer' and part-timers' not having office hours for the students to plan teaching and learning process, carry out researches and/or pose any questions university students would likely to ask them and finally most of the academicians' not having necessary $\mathrm{PhD}$ and/or EdD degrees to be able to teach at the university.

Dangers: TUSs would face dangers regarding easiness in entering casinos, easiness to gamble, easiness to drink and take alcohol in bars, easiness to enter bet offices and casinos, easiness to find heroine and/or its derivatives, and easiness to enter places where prostitutes work who even do not have regular hygiene check-ups.

Higher education fees are very high in NC. Actually, cost of living is very high, too. Internet fees, hiring cost of a house, going out with friends.... are really expensive. When you meet your friends in a café at a popular street, you need huge amount of money to pay even for a coffee. It is not unusual to pay huge amounts of money even for a coffee at a café at a popular street, however there are not much places for students to go. Students need places to meet, to study, to chat, to discuss issues at a proper way; however, we don't have such proper places for university students. Lack of these student meeting places make them go to pubs, casinos etc. some male students tend to go some places where bad women work. You understand what I mean. It may be that, and I believe it is that these women are not taken to the hospital regularly for their hygiene check ups. This is so ridiculous, because students have higher proportion of getting infectious illness. They come to NC to study, to improve themselves and get a diploma. But someone's greediness makes the students to be trapped. Businessmen want to earn much money, especially from students, because NC is an island, which is full of universities (TUS10).

Motivational factors in studying in a foreign country combine push and pull factors which are "Institution and academic reputations, marketability of the degree, low tuition fees compared to home institution, low cost of living, safe country for study, similarity of education systems as well as cultural proximity" [1]. Similarly, students' satisfaction with the university and being healthy are the factors increasing ratio of international students' studying abroad [19]. However, there are dangers international students may face. They may be country-specific dangers such as easiness to enter casinos to gamble, easiness to drink and take excess alcohol in bars, easiness to enter bet offices and casinos; easiness to find heroine and/or its derivatives and easiness to enter places where prostitutes work who even do not have regular hygiene check-ups. However, such kinds of dangers decrease students' success level, adaptation level and motivation level at the higher education sector. It is better to promote some concrete solutions by politicians, higher education providers and/or people from the Ministry of National Education for the international students in order to decrease the level of the dangers mentioned above.

\section{Theme 4: Expected factors}

Campus quality: TUSs expect to have a campus life including effective use of instructional technology, which is 
safe, covering effective social facilities that attract attention of students and having shorter distance to classes.

\begin{abstract}
Most of our lecturers carry their overhead projectors with them to the class because in most of our classes there are not any instructional technologies. I think it should not be very difficult and expensive to set up a projector in each class. Managers of the university do not invest on the materials we need in our classes. They only invest on the buildings. However, we pay for the university fee; I believe that the university fee covers having such kind of technologies and materials for our education (TUS49).
\end{abstract}

I don't live at the university dormitories. When I first arrived to the university, I was at the dormitory. I didn't have to wait for the buses. I could walk to my classes easily. I had very easy access to my classes. I could join many activities of the university; I could go swimming after my classes regularly. In the second year, I couldn't find space at the university dormitories when I came back from Turkey. Now, I live in the city center. I don't live closer to the university, so I can't walk to the university. I need to have easier transportation to the university. Actually, my university has regular bus services to the university. I use university buses as part of my transportation. I may not join most of the activities held in university after classes; for example I can't go swimming because I don't want to carry an extra bag containing materials I need for swimming. I can say that campus life is the best. Life outside the campus may have some restrictions for the students who would like to join activities held in the campus (TUS31).

Effective use of instructional technology supplements effective learning and teaching. Face-to-face-courses, for instance, is one of its type and social networking technology supplements face-to-face-courses. Such kind of courses improves the quality of community sense of students and actively encourages communities of practice in the higher education context. It is confirmed that social networking technology develops most of the participants' positive feeling on social connectivity and most of the participants reveal approved feelings on learning experiences [30]. Similarly, Surry and Land [52] designed a framework of which strategies are on gaining attention, gaining relevancy, building confidence and being satisfied. These strategies on the framework are helpful in using computer assisted instruction and constructivism. They facilitate to increase motivation. On the other hand, alternative instructional technology usage, such as instructional learning and teaching via Facebook and/or some kinds of weblog services, suggests teachers to be aware on the level of motivation of the students, affective learning and classroom climate [39]. Higher education students reveal that most of the classes do not have necessary technological equipment but some of the academicians carry their technological equipment with them every class. Dormitories have Internet supplies, but Internet supplies do not work at the uppermost quality. Similarly, most of the students agree that they can access to the classes quickly and easily. They feel themselves very safe in the campus. Also, they can join some of the social facilities whenever they want. They can do sport, go to the cinema, do their group assignments at the library's group rooms, and/or visit their friends whenever they want. They do not feel any negative pressure on them.

Valuing the self: TUSs expect to develop their self-reliance, self-esteem, self-appraisal, self-worth and self-determination as well as get full support from parents and get closer support from friends.

As a university student, I want to feel myself very precious. I have started the faculty very recently; this is my first semester. I am still a teenager (I am 19), a very young person. My family has been contributing for my personal and academic grown, has just sent me to the university to complete my higher education. We chose North Cyprus universities together for this purpose. After moving here, I have just changed my home, my school, my friends, my environment, my country, my culture... everything that makes my life valuable for me. Now I am here. I expect my university life to develop and improve my self-reliance, my self-esteem, my self-appraisal, my self-worth and my self-determination. I also need to grow closer relationships with the new friends. I know I need their full support because they are my new members in my life, and I will see them mostly. I need to get full support from my family and I need to get full support from my new friends. Actually, I need to strive degree for myself. Otherwise, I can't survive; I can't take future steps (TUS17).

A study confirms that factors contributing to positive self-esteem and self-efficacy had higher level of general satisfaction on the education program, how long time spent on self-study and on being male [11]. Measurement in self-efficacy has been found to be potential consequence for interventions in education [33]. Students' general state of anxiety and self-esteem might affect general anxiety level of students [56]. Similarly, Hong, Lin, Wang, Chen and Yu [29] find low achieving students' scores (Experimental Group) are significantly higher scores on self-efficiency and self-worth than low-achieving (Comparison group I) and moderate or high academic achieving (Comparison group II) students' scores. It is also found that low-achieving students' scores are significantly affected by functional group counselling [29]. On the other hand, contingent self-esteem is an indicator of psychological vulnerability. There has been found an increase in the influence of contingent self-esteem on socialization processes[27]. Participants of the current study reveal that as young people, they value themselves. They value their self-reliance, their self-esteem, their self-appraisal, their self-worth and their self-determination. They believe that valuing themselves worth getting support from the higher education providers, from their parents and from their friends. 


\section{Conclusion and Recommendations}

\section{Managing Conversions}

Turkish university students have pull and push academic mobility factors for studying in NC. Pull factors are factors attracting them to study in NC as before academic mobility. Push factors are factors they mostly face while they are studying in $\mathrm{NC}$ as after academic mobility. Pull factors include educational quality, personal contribution and adaptation processes whereas push factors cover student life and family factors, academic studies and departmental issues, familiarities and country factors.

Higher education service providers for international students require to support service provision regarding students' expectations and to meet actual needs of the students in order to obtain higher levels of students' satisfaction with their international experience [50]. Therefore, academic mobility of students is recommended to have an assistance and control system from beginning of the higher education to the end of their education life in NC. Assistance and controlling system should be maintained. This study recommends a new concept on the learning and growing at another culture and country. New comers require assistance and control. Otherwise, they may face gambling, take alcohol excessively, damage and hurt themselves and/or give disturbance to the environment. Through time, they require control on how they manage their health issues, accommodation, transport, communication, academic issues, social life, learning, adaptation process and growth.

\section{Note}

*The abstract of this paper was presented at 2nd International Conference on Lifelong Learning and Leadership for All (ICLEL-16), in Liepaja on July, 21-23, 2016.

\section{REFERENCES}

[1] Ahmad, S. Z., \& Buchanan, F. R. (2016). Motivation factors in students decision to study at international branch campuses in Malaysia. Studies in Higher Education. Doi: 10.1080/03075079.2015.1067604

[2] Anderman, L. H. (2003). Academic and social perceptions as predictors of change in middle school students' sense of school belonging. The Journal of Experimental Education, 72(1), 5-22. Doi: 10.1080/00220970309600877

[3] Azmat, F., Osborne, A., Rossignol, K. L., Jogulu, U., Rentschler, R., Robottom, I., \& Malathy, V. (2013). Understanding aspirations and expectations of international students in Australian higher education. Asia Pacific Journal of Education, 33(1), 97-111. Doi: http://dx.doi.org/10.1080/0218 8791.2012.751897

[4] Baron, P., \& Corbin, L. (2012). Student engagement: Rhetoric and reality. Higher Education Research and
Development, 31(6), 759-772. Doi: 10.1080/07294360.2012.6 55711

[5] Bartram, B. (2008). Supporting international students in higher education: Constructions, cultures and clashes. Teaching in Higher Education, 13(6), 657-668. Doi: 10.1080/1356251080 2452384

[6] Beaven, A., \& Golubeva, I. (2016). Intercultural preparation for future mobile students: A pedagogical experience. Language and Intercultural Communication, 16(3), 491-501. Doi: 10.1080/14708477.2016.1168044

[7] Beech, S. E. (2015). International student mobility: The role of social networks. Social and Cultural Geography, 16(3), 332-350. Doi: 10.1080/14649365.2014.983961

[8] Beer, C., \& Lawson, C. (2016). The problem of student attrition in higher education: An alternative perspective. Journal of Further and Higher Education, 1-12. Doi: 10.1080/0309877X.2016.1177171

[9] Ben-Tsur, D. (2009). The impact of conflict on international student mobility: A case study of international students studying in Israel. International Studies in Sociology of Education. Special Issue: Globalisation, Higher Education and the Struggle for Change (Part 2), 19(2), 135-149. Doi: $10.1080 / 09620210903257257$

[10] Bianchi, S. (2013). Satisfiers and dissatisfiers for international students of higher education: An exploratory study in Australia. Journal of Higher Education Policy and Management, 35(4), 396-409. Doi: 10.1080/1360080X.2013.8 12057

[11] Bonsaksen, T. (2015). Predictors of general self-efficacy and self-esteem in occupational therapy students: A cross-sectional study. Occupational Therapy in Mental Health, 31(3), 298-310. Doi: 10.1080/0164212X.2015.105553 6

[12] Borowa, D., Robitschek, C., Harmon, K. A., \& Shogemoto, Y. (2016). Posttraumatic stress and growth in student service members and veterans: The role of personal growth initiative. Journal of American College Health, 64(7), 527-534. Doi: 10.1080/07448481.2016.1188395

[13] Brown, L., \& Holloway, I. (2008). The initial stage of the international sojourn: Excitement or culture shock. British Journal of Guidance and Counselling, 36(1), 33-49. Doi: $10.1080 / 03069880701715689$

[14]Brooks, R., \& Waters, J. (2010). Social networks and educational mobility: The experiences of UK students. Globalisation, Societies and Education. Special Issue: Regulatory Regionalism and Higher Education, 8(1), 143-157. Doi: 10.1080/14767720903574132

[15] Cardoso, S., Rosa, M. J., \& Stensaker, B. (2016). Why quality in higher education not achieved? The view of academics. Assessment and Evaluation in Higher Education, 41(6), 950-965. Doi: 10.1080/02602938.2015.105 2775

[16] Corbett, A. (2014). The globalisation challenge for European higher education: Convergence and diversity, centres and peripheries. European Journal of Higher Education. Special Issue: Transformation in post-socialist higher education systems, 4(3), 297-300. Doi: 10.1080/21568235.2014.903575

[17] Daniels, J., \& Brooker, J. (2014). Student identity development 
in higher education: Implications for graduate attributes and wok-readiness. Educational Research, 56(1), 65-76. Doi: 10.1080/00131881.2013.874157

[18] Fengliang, L. (2012). Financing higher education: Lessons from China. Irish Educational Studies, 31(2), 191-206. Doi: 10.1080/03323315.2011.634094

[19]Finn, M., \& Darmody, M. (2016). What predicts international higher education students" satisfaction with their study in Ireland? Journal of Further and Higher Education, 1-11. Doi: 10.1080/0309877X.2015.1135887

[20] Freeman, T. M., Anderman, L. H., \& Jensen, J. M. (2007). Sense of belonging in college freshmen at the classroom and campus level. The Journal of Experimental Education, 75(3), 203-220. Doi: 10.3200/JEXE.75.3.203-220

[21] Furnham, A. (1993). Communicating in foreign lands: The cause, consequences and cures of culture shock. Language, Culture and Curriculum. Special Issue: Culture and Language Learning in Higher Education, 6(1), 91-109. Doi: $10.1080 / 07908319309525140$

[22] Gill, S. (2007). Overseas students' intercultural adaptation as intercultural learning: A transformative framework. Compare: A Journal of Comparative and International Education, 37(2), 167-183. Doi: 10.1080/0305792060116551 2

[23] Goodenow, C., \& Grady, K. E. (1993). The relationship of school belonging and friends' values to academic motivation among urban adolescent students. The Journal of Experimental Education, 62(1), 60-71. Doi: 10.1080/00220973.1993.9943831

[24] Griffioen, D. M. E., Jong, U. D., \& Jak, S. (2013). Research self-efficacy of lecturers in non-university higher education. Innovations in Education and Teaching International, 50(1), 25-37. Doi: 10.1080/14703297.2012.746 512

[25] Gu, Q., Schweisfurth, M., \& Day, C. (2010). Learning and growth in a foreign context: Intercultural experiences of international students. Compare: A Journal of Comparative and International Education. Special Issue: Globalization, Educational Governance and

Decentralization, 40(1), 7-23. Doi: 10.1080/03057920903115 983

[26] Gunuc, S., \& Kuzu, A. (2015). Student engagement scale: Development reliability and validity, Assessment and Evaluation in Higher Education, 40(4), 587-610. Doi: 10.1080/02602938.2014.938019

[27] Hallsten, L., Rudman, A., \& Gustavsson, P. (2012). Does contingent self-esteem increase during higher education? Self and Identity, 11(2), 223-236. Doi: 10.1080/15298868.201 0.544872

[28] Harland, T. (2012). Higher education as an open-access discipline. Higher Education Research and Development. Special Issue: The Development of Higher Education as a Field, 31(5), 703-710. Doi: 10.1080/07294360.2012.689275

[29] Hong, Z. R., Lin, H. S., Wang, H. H, Chen, H. T., \& Yu, T. C. (2012). The effects of functional group counselling on inspiring low-achieving students' self-worth and self-efficacy in Taiwan. International Journal of Psychology, 47(3), 179-191. Doi: 10.1080/00207594.2011.59 0494
[30] Hung, H. T., \& Yuen, S. C. Y. (2010). Educational use of social networking technology in higher education. Teaching in Higher Education, 15(6), 703-714. Doi: 10.1080/13562517.20 10.507307

[31] Irwing, J. A., \& Williams, D. I. (1999). Personal growth and personal development: Concepts clarified. British Journal of Guidance and Counselling, 27(4), 517-526. Doi: 10.1080/03069889908256287

[32] Jaspal, R. (2015). Constructing and protecting identity in a diverse higher education context. Perspectives: Policy and Practice in Higher Education, 19(4), 127-134. Doi: 10.1080/13603108.2015.1071291

[33] Jones, A., \& Sheppard, L. (2012). Developing a measurement tool for assessing physiotherapy students' self-efficacy: A pilot study. Assessment and Evaluation in Higher Education, 37(3), 369-377. Doi: 10.1080/02602938.20 10.534765

[34] Jungblut, J., Vukasovic, M., \& Stensaker, B. (2015). Student perspectives on quality in higher education. European Journal of Higher Education, 5(2), 157-180. Doi: 10.1080/21568235.2 014.998693

[35] Kahu, E., R. (2013). Framing student engagement in higher education. Studies in Higher Education, 38(5), 758-773. Doi: 10.1080/03075079.2011.598505

[36] Krause, K. L., \& Coates, H. (2008). Students' engagement in first-year university. Assessment and Evaluation in Higher Education, 33(5), 493-505. Doi: 10.1080/0260293070 1698892

[37]Lee, M. N. N. (2008). Restructuring higher education: Public-private partnership. Journal of Asian Public Policy. Special Issue: Tensions Between Education as a Public Good and as a Private Commodity, 1(2), 188-198. Doi: $10.1080 / 17516230802094494$

[38] Lin, I. J. H. (2014). Realigning capital portfolios: International students' educational experiences in higher education. Asia Pacific Journal of Education,34(3), 366-380. Doi: 10.1080/02188791.2013.860009

[39] Mazer, J. P., Murphy, R. E., \& Simonds, C. J. (2007). I'll see you on Facebook: The effects of computer-mediated teacher self-disclosure on student motivation, affective learning and classroom climate. Communication Education 56(1), 1-17. Doi: $10.1080 / 03634520601009710$

[40] Ma, X. (2003). Sense of belonging to school: Can schools make a difference? The Journal of Educational Research, 96(6), 340-349. Doi: 10.1080/00220670309596617

[41] Matook, S., Cummings, J., \& Bala, H. (2015). Are you feeling lonely? The impact of relationship characteristics and online social network features on loneliness. Journal of Management Information Systems, 31(4), 278-310. Doi: $10.1080 / 07421222.2014 .1001282$

[42] McKenzie, K., \& Schweitzer, R. (2001). Who succeeds as university? Factors predicting academic performance in first year Australian university students. Higher Education Research and Development, 20(1), 21-33. Doi: 10.1080/07924360120043621

[43] Mobility. (n.d). Cambridge Dictionaries Online. http://diction ary.cambridge.org/dictionary/english/mobility

[44] Nkrumah-Young, K. K., \& Powell, P. (2011). Exploring higher 
education financing options. European Journal of Higher Education, 1(1), 3-21. Doi: 10.1080/21568235.2011.5 77181

[45] Pere, E., \& Minxhozi, L. (2011). Financing Albanian higher education: Growth between the public and private sectors. European Journal of Higher Education 1(2-3), 202-219. Doi: 10.1080/21568235.2011.596668

[46] Pittman, L. D., \& Richmond, A. (2008). University belonging, friendship quality, and psychological adjustment during the transition to college. The Journal of

Experimental Education, 76(4), 343-362. Doi: 10.3200/JEXE. 76.4.343-362

[47] Pitman, L. D., \& Richmond, A. (2007). Academic and psychological functioning in late adolescence: The importance of school belonging. The Journal of Experimental Education, 75(4), 270-290. Doi: 10.3200/JEXE.75.4.270-292

[48] Prince, E. J., \& Hadwin, J. (2013). The role of a sense of school belonging in understanding the effectiveness of inclusion of children with special education needs. International Journal of Inclusive Education, 17(3), 238-262. Doi: 10.1080/13603116. 2012.676081

[49] Raaper, R. (2016). Academic perceptions of higher education assessment processes in neoliberal academia. Critical Studies in Education, 57(2), 175-190. Doi: 10.1080/17508487.2015.1 019901

[50] Roberts, P. \& Dunworth, K. (2012). Staff and student perceptions of support services for international students in higher education: A case study. Journal of Higher Education Policy and Management, 34(5), 517-528. Doi: 10.1080/1360080X.2012.716000

[51] Sheard, J., Carbone, A., \& Hurst, A. J. (2010). Student engagement in first year of an ICT degree: Staff and student perceptions. Computer and Science Education, 20(1), 1-16. Doi: 10.1080/08993400903484396

[52] Surry, D. W., \& Land, S. M. (2000). Strategies for motivating higher education faculty to use technology. Innovations in Education and Training International, 37(2), 145-153. Doi: $10.1080 / 13558000050034501$

[53] Thite, M., Srinivasan, V., Harvey, M., \& Valk, R. (2009).
Expatriates of host-country origin: Coming home to test the waters. The International Journal of Human Resource Management, 20(2), 269-285. Doi: 10.1080/09585190802670 532

[54] Warner, R., \& Miller, J. (2015). Cultural dimensions of feedback at an Australian university: A study of international students with English as an additional language. Higher Education Research and Development, 34(2), 420-435. Doi: 10.1080/07294360.2014.956695

[55] Wilcox, P., Winn, S., \& Fyvie-Gauld, M. (2005). It was nothing to do with the university, it was just the people: The role of social support in the first-year experience of higher education. Studies in Higher Education, 30(6), 707-722. Doi: $10.1080 / 03075070500340036$

[56] Yan, C. H. (2006). Factors affecting the state anxiety level of higher education students in Macau: The impact of trait anxiety and self-esteem. Assessment and Evaluation in Higher Education, 31(6), 709-725. Doi: 10.1080/0260293060 0760934

[57] Yiljoki, O. H., \& Ursin, J. (2013). The construction of academic identity in the changes of Finnish higher education. Studies in Higher Education. Special Issue: The purposes of higher education: Responses from a globalized world, 38(8), 1135-1149. Doi: 10.1080/03075079.2013.83303 6

[58]Zepke, N. (2015). Student engagement research: Thinking beyond the mainstream. Higher Education Research and Development, 34(6), 1311-1323. Doi:10.1080/07294360.2015 .1024635

[59]Zgaga, P. (2013). Higher education research and higher education policy in South-East Europe. European Journal of Higher Education. Special Issue: The Past, Present and Future of Higher Education Research: Between Scholarship and Policy making, 3(3), 280-294. Doi: 10.1080/21568235.2013.8 19671

[60] Zhou, Y., Jindal-Snape, D., Topping, K., \& Todman, J. (2008). Theoretical models of culture shock and adaptation in international students in higher education. Studies in Higher Education, 33(1), 63-75. Doi: 10.1080/030750707017 94833 